\title{
Escrevendo-se na cidade: Exu e o Guia afetivo da periferia, de Marcus Vinicius Faustini
}

Vinicius Mariano de Carvalho ${ }^{1}$

\author{
Era madrugada \\ e o luar clareava toda rua \\ Um moço rico tão garboso caminhava \\ Com sorriso me olhava \\ tinha fogo em seu olhar \\ Mas ele é meu amigo de fé \\ Meu exu camarada \\ O seu axé está na rua \\ o seu nome é Tranca Ruas \\ ele é o rei da encruzilhada \\ Ponto de Exu Tranca-Rua
}

O livro de estreia de Marcus Vinicius Faustini, o Guia afetivo da periferia, publicado em 2009, apareceu no contexto da literatura brasileira contemporânea como uma novidade em vários sentidos. Foi publicado em uma coleção, a Tramas urbanas, que tem como objetivo evidenciar a produção cultural das periferias urbanas brasileiras como uma voz alternativa e própria de sujeitos que constroem sentidos a partir da própria realidade em que vivem, contrapondo-se com isso à tradicional e simplificadora relação entre periferias e violência, tráfico de drogas e mortes. O livro também foi inovador em sua estrutura, combinando ficcionalização autobiográfica com fotografias (do próprio autor), construindo uma narrativa questionadora e inovadora (Delgado, 2013; Drumond, 2013).

Outro aspecto extremamente relevante na obra é sua filiação ao tecido urbano, construindo uma sintaxe que é a da circulação urbana, transitando entre os espaços considerados centro e periferia, sem hierarquização dos mesmos, expressando com isso o sentido do título da obra. $\mathrm{O}$ autornarrador-personagem escreve-se na cidade, fenomenologicamente, e não escreve a cidade. Nas palavras de Dalcastagnè:

E, assim, ele [autor-narrador-personagem] vai caminhando pela cidade, aprendendo e apreendendo-a, construindo, em pouco tempo, uma cartografia própria, que desliza em sucessivas

\footnotetext{
${ }^{1}$ Doutor em literatura românica e professor do King’s Brazil Institute - King’s College London, Londres, Inglaterra. E-mail: rennavmc@googlemail.com
} 
descobertas (...). Seguindo-o, podemos ter um vislumbre da cidade como uma escrita possível, tal como propunha Michel de Certeau. Uma escrita aberta, uma vez que permite ao leitor, mesmo aquele que nunca viveu no Rio de Janeiro, inscrever-se ali, com suas próprias trajetórias urbanas (Dalcastagnè, 2014, p. 37).

Leila Lehnen, em seu recente livro Citizenship and crises in contemporary Brazilian literature (2013), dedica um capítulo inteiro a esse romance inaugural de Faustini e também observa como há nesta obra uma quebra com o aceito e pouco discutido paradigma da cidade partida entre periferia e centro, ou entre favela e asfalto. Lehnen chama a atenção para como, no processo de construção do que chama de pontes metafóricas, o autor reorganiza o tecido da cidade no texto narrativo. Nas palavras de Lehnen:

O Guia afetivo da periferia concentra-se em territórios comuns e constrói pontes narrativas entre diferentes terrenos socioeconômicos e culturais da metrópole. Construindo pontes metafóricas, e atravessando-as, o narrador do Guia afetivo da periferia se estabelece como um cidadão de toda a urbe, e não como um sujeito relegado a sua periferia geográfica e figurativa (Lehnen, 2013, p. 160).

O aspecto da escrita da cidade de Faustini é também ressaltado no prefácio da obra, escrito por Luiz Eduardo Soares. Diz o sociólogo: “O movimento do texto de Faustini é sinuoso como suas trajetórias urbanas, e tortuoso como seu percurso existencial" (Soares, 2009, p. 17). A sintaxe do texto de Faustini está na rua e seu autor-narradorpersonagem não apenas escreve o texto, mas, de certa maneira, o performatiza. E esse texto é a cidade em si, portanto sua escritura é uma performatização da cidade. Esse autor-narrador-personagem se torna também ator, e nessa performance dinâmica não quebra paradigmas, mas os reorganiza em um tecido não usual nas representações do urbano. Ainda é Soares em seu prefácio à obra que diz:

Atravessando todos os quadrantes da cidade, o narrador embaralha as cartas, os mapas, as visões cristalizadas - quando não estigmatizantes - e recontextualiza identidades, flexibilizando-as, combinando-as como um operador sincrético. Hermes - o narrador/máscara/cão de seu tempo - traduz os códigos entre si e fluidifica os canais de comunicação, editando a seu modo um Rio de Janeiro sem a cicatriz da dicotomia centroperiferia. Quem gravita em torno de quem? Onde é o umbigo do 
mundo? Movendo-se para cima, para baixo, aquém, além e através, faz-se, o autor-máscara, na tessitura de conexões inusitadas, seta em movimento, deslocando poderes, reescrevendo geografias, desenhando, em seu percurso pedestre e libertário, o arco de novos encontros e as inflexões de esquinas improváveis (Soares, 2009, p. 19, grifo nosso).

Nesse ponto chego à proposta de leitura que gostaria de desenvolver aqui. Lendo cuidadosamente essa descrição de Soares, de imediato me remeto à mitologia do Orixá Exu, mais que a de Hermes. E aqui percebo outra novidade dessa obra de Faustini. Sem quebrar paradigmas interpretativos, mas os reorganizando em outra sintaxe, o Guia afetivo da periferia me convida a uma leitura com a hermenêutica dessa entidade das religiões brasileiras de matriz africana como outra novidade performativa do texto. O que estou dizendo é que sim, podemos concordar com Soares que o autor-narrador-personagem-ator figura um Hermes, mas me parece que, se o lermos como um Exu, teremos outra inovação advinda dessa obra, agora em uma perspectiva de crítica.

Nos tópicos subsequentes irei expor mais claramente essa proposta de uma hermenêutica literária a partir da mitologia dos Orixás em geral e desenvolver o caso particular que proponho aqui, de se ler o Guia afetivo da periferia tendo como foco a mitologia de Exu.

\section{A mitologia dos Orixás como hermenêutica literária}

Não é novidade nos depararmos, nos estudos literários, com o uso recorrente de figuras da mitologia grega como recursos hermenêuticos na construção de interpretações e análises de personagens e \ou eventos narrativos. Portanto, a comparação que Luiz Eduardo Soares faz entre o narrador personagem do Guia afetivo da periferia com Hermes soa completamente familiar e já traz em si uma série de significados, imediatamente reconhecíveis, uma vez se conhecendo a figura mitológica em questão.

Boa parte do que se considerava "erudição" na formação escolar e acadêmica baseava-se no conhecimento das fontes mitológicas grecoromanas. Saber reconhecê-las e interpretar o mundo contemporâneo e suas obras literárias e artísticas à luz dessa mitologia ocupou boa parte da formação de muitas pessoas, e muitas produções literárias (e suas 
análises) são diretamente referentes a essa mitologia (quantos Orfeus não conhecemos em todas as artes, de todos os tempos?).

O que chama atenção, no entanto, é que em um contexto crítico póscolonial e no qual os estudos de subalternidade ocupam um espaço já bastante privilegiado em nosso ambiente de estudos literários e culturais e, mais ainda, em um momento histórico de reconhecimento de valores e tradições extremamente relevantes na composição do ambiente sociocultural contemporâneo e que foram negligenciados no passado (vide os esforços em incluir estudos de história da África e literaturas africanas nos currículos escolares brasileiros, por exemplo), ainda não tenhamos nos debruçado com mais afinco ao estudo da mitologia dos Orixás - e por extensão de toda a mitologia das religiões brasileiras de matrizes múltiplas e sincréticas - como chaves hermenêuticas para análises literárias.

Analisar obras literárias e artísticas em geral, tendo como referencial mitológico a(s) epistemologia(s), a(s) cosmologia(s) e a(s) ontologia(s) forjadas sócio-historicamente no ambiente sincrético (por que não dizer, antropofágico) brasileiro é, a meu ver, sair do papel de objeto para a posição de sujeito crítico, que rompe (sem revoluções) com paradigmas subalternizantes de "explicação do mundo". É apresentar alternativas críticas não homogeneizadoras. Enfim, ser sujeito de uma crítica cultural que se constitui com uma outra sintaxe.

Os estudos de religião - sejam eles derivativos da sociologia, filosofia ou antropologia, ou mesmo da própria teologia - já nos forneceram compreensões amplas da mitologia dos Orixás, o que, associado com a compreensão vivencial dessa mitologia no contexto sócio-histórico brasileiro, nos garante um repertório suficiente de entendimento do rico e variado (e crítico) universo afro-ameríndio-brasileiro. Percebo esse material crítico como um instrumental ampliador do espaço de voz de sujeitos subalternados tanto no contexto brasileiro quanto em um contexto global, ressaltando a voz original da crítica brasileira no mundo. Um criterioso estudo da mitologia afro-ameríndia-brasileira como hermenêutica colabora na reversão do quadro do Brasil como apenas fornecedor de obras a serem analisadas e insere uma originalidade critica nos estudos literários de perspectiva pós-colonial.

Neste artigo não tenho condições de propor uma ampla proposta nesse sentido. As limitações são muitas e vão desde o espaço do próprio artigo, o contexto da apresentação do mesmo até as limitações de 
conhecimento deste próprio autor. O que proponho é uma possível leitura hermenêutica da mitologia do Orixá Exu na obra de Marcus Vinicius Faustini, visto que, desde a minha primeira leitura da obra, saltou-me aos olhos o paralelo entre o personagem-narrador e o Orixá Exu. No próximo tópico farei uma breve descrição das características desse Orixá, valendo-me de estudos vários sobre o mesmo, e, em seguida, discorrerei sobre como o leio na obra de Faustini.

\section{Exu}

Exu é possivelmente o Orixá de história e entendimento mais complexos no universo da mitologia das religiões brasileiras de matriz africana, também o que mais povoa o imaginário popular, mesmo daqueles que não professam nenhuma das religiões nas quais o Orixá é entidade-chave.

Em virtude das associações com o universo religioso cristão, Exu foi associado ao diabo (Prandi, 2001), no processo de sincretismo com o catolicismo, e isso foi o bastante para sua figura e representações serem sempre revestidas de algum distanciamento entre aqueles que não conhecem sua significação. Com o crescente número de grupos religiosos neopentecostais, tanto entre evangélicos quanto entre católicos, a demonização das religiões de matriz africana no Brasil ganhou contornos de intolerância contemporaneamente, e o Exu, com todas suas manifestações, é o que se torna menos compreendido entre todos os outros Orixás (Silva, 2005).

Não pretendo aqui traçar um estudo aprofundado sobre esse Orixá. $\mathrm{O}$ que chamarei à atenção são as características de Exu que nos permitam vê-lo como uma figura mitológica que oferece uma chave hermenêutica na leitura da obra de Faustini. Estou consciente das diferenças conceituais entre as distintas religiões de matriz africana no Brasil e de como interpretam esse Orixá. Busco, contudo, algumas linhas gerais que possam inclusive provocar estudos posteriores mais aprofundados sobre a proposta aqui levantada.

A riqueza da mitologia desse Orixá, contudo, está longe da simplificação intolerante de associá-lo ao diabo cristão. Exu é o princípio dinâmico que coloca tudo em movimento; ele mesmo é movimento, e, portanto, transporte, comunicação. “O orixá Exu tem esse encargo de transportador" (Prandi, 2005, s.p.). É ele que permite 
passagens, inclusive entre mundos e universos, por isso é invocado sempre no início de qualquer ritual, como garantia de que todos os caminhos estarão abertos. "Exu propicia essa comunicação, traz suas mensagens, é o mensageiro" (Prandi, 2005, s.p.).

Orixá que estabelece a comunicação, nele está contido o princípio dinâmico da transformação e movimento. É o possuidor do dom da ubiquidade, de estar em toda parte, em ação. Exu é responsável por transportar o axé (a força mágica sagrada), por isso recebe os tributos iniciais - o padê, a oferenda inicial (Assunção, 2010, p. 165).

De acordo com Prandi (2005), a característica principal de Exu é o movimento, ele é o movimento. Já que vida é movimento, mudança, "pulsar permanente", portanto, nada pode acontecer sem ele, nem mesmo o pensamento. Pelo fato de ser movimento, Exu é por natureza transformador, provocador e sedutor. "Exu é aquele que tem o poder de quebrar a tradição, pôr as regras em questão, romper a norma e promover a mudança" (Prandi, 2005, s.p.). Daí vem sua associação com o diabo e ao mesmo tempo o temor que provoca. Ainda com Prandi, "Não é, pois, de se estranhar que seja temido e considerado perigoso, posto que se trata daquele que é o próprio princípio do movimento, que tudo transforma, que não respeita limites" (Prandi, 2005, s.p.).

Santos (1976) afirma que a Exu foi dada a capacidade de dominar todas as palavras e de jogar com todas as significações. Com isso, ele se torna mensagem, mediador e intérprete, ao mesmo tempo, e permite aos outros Orixás que comuniquem entre si e os homens. Na mitologia dos Orixás é, portanto, o mensageiro.

Nessa condição manifesta-se de forma diversa e múltipla em muitas expressões religiosas de matriz africana no Brasil, com muitos nomes e formas. Os Exus e pombagiras são geralmente denominados na umbanda "povos de rua". Vivem nas encruzilhadas e são utilizados como intermediadores em diversos assuntos do mundo material como dinheiro, relacionamentos, negócio, vinganças etc. Esses "povos de rua", no caso da umbanda, são espíritos que já estiveram encarnados e que, quando vivos, eram marginalizados e segregados pela sociedade, transitavam com facilidade na boemia e no submundo marginal. As diversas manifestações de Exu, portanto, conhecem todas as falhas humanas, seus vícios e virtudes e por isso não atuam com julgamentos morais.

O que ele [Exu] exprime, sobretudo, é a natureza contraditória da sociedade - mistura instável de ordem e desordem, de 
conformidade e de não conformidade - do que resulta sua própria natureza, sua instabilidade essencial, expressando em seu imaginário desejos transgressores, como contestação do lugar atribuído a essa prática religiosa estigmatizada na sociedade brasileira (Assunção, 2010, p. 170-171).

Ocupando o espaço do entremundos, a rua, não estando em nenhum lugar fixo, seja ele físico ou moral, Exu representa uma voz contraditória, uma insatisfação com o status quo, uma quebra do lugar comum seguro. "Eles [os Exus] perturbam, transgridem, subvertem; desafiam os poderes e as potências superiores. Há uma lógica da ordem, que se opõe a uma lógica da contradição e da incerteza" (Assunção, 2010, p. 169).

Muito longe da demonização que um senso comum religioso procura atribuir a esse Orixá, ele é na verdade uma força antagônica, que estabelece uma crítica provocativa do sujeito e de seu estar no mundo. O simbolismo de Exu, portanto, encontra eco não apenas no universo do imaginário mas também do real, recordando o significado último do que é liberdade. Ele “expressa simbolicamente as incertezas humanas frente ao debate com os limites do tempo, com as condições sociais estabelecidas, afirmando sua liberdade frente às imposições" (Trindade 1985, p. 80).

Como dito anteriormente, esse esboço de características mitológicas do Orixá Exu não são completas, ou mesmo sistematicamente elaboradas. Busquei aqui apontar algumas das características desse Orixá que permitirão a hermenêutica proposta neste texto de se ler no narrador do Guia afetivo da periferia a figura mitológica de Exu.

\section{O Exu no Guia afetivo da periferia}

O que primeiro me chama a atenção na postura do autor-narradorpersonagem-ator do Guia afetivo da periferia é a escolha da rua como o espaço sintático de sua narrativa. Não é a periferia, nem o centro o espaço da narrativa, mas a circulação entre todos os espaços urbanos. Literalmente: "Na rua que já foi conhecida como Beco da Luxúria, hoje chamada 20 de Abril, perto do Campo de Santana no centro do Rio, fica o lugar onde costurei essas partes que agora sinto ligadas pela circulação do sangue carregado de memórias" (Faustini, 2009, p. 30). A relação existencial entre autor-narrador-personagem-ator e a cidade é evidente nesse trecho, no qual a fisiologia da circulação sanguínea se mistura ao ato performático da costura, do ato de tecer, tendo como 
origem a rua. E não uma rua qualquer, senão aquela que fora conhecida pela alcunha do prazer, Beco da Luxúria.

Como Exu, o autor-narrador-personagem-ator é "povo de rua", ali conhece a todos, ali trama sua existência: "Assim, passei a mapear o centro do Rio de Janeiro de acordo com as minhas possibilidades de sobrevivência" (Faustini, 2009, p. 54). Na rua, realiza-se em diversas identidades, reais ou imaginadas. Ecoando o par antitético "casa x rua", elaborado pelo antropólogo Roberto DaMatta (1997), Faustini na verdade rompe também com mais essa antinomia, reorganizando esses paradigmas, intermediando mundos, como Exu: "Ele tem o mesmo amor pela casa e pela rua. Ficar na esquina é tão importante quanto ter um quarto" (Faustini, 2009, p. 105).

O Guia afetivo da periferia se faz, portanto, como um guia entre mundos, todos entrecruzados nas ruas da cidade. Não é como um guia de prédios e locais, mas da circulação pelas ruas, locus da substanciação da realidade.

Era a confirmação de que, domingo a domingo, mesmo sem dinheiro, fazia mais sentido andar pela rua do que ficar em casa. $\mathrm{Na}$ espera do trem, observava as pessoas e criava pequenas histórias para cada uma. Era meu território particular de invenção (Faustini, 2009, p. 35).

Como Exu, o autor-narrador-personagem-ator não foge ao antagonismo, ao contrário, aceita-o e metaforiza-o (aqui bem na acepção grega do termo, transporta-o); comunga universos, valores, imagens, sentimentos, sensações e, fenomenologicamente, faz-se rua, faz-se cidade:

Estavam ali, dispostos naquele momento diante de mim, engolindo a madrugada como eu engolia o churrasquinho, universos que até então eu acreditava antagônicos: churrasquinho, filme pirata, cheiro de mijo, Paulo Coelho, Dostoievski, aço, concreto, parede sem emboço e uma pichação da época do Brizola (Faustini, 2009, p. 33).

Ainda, como Exu, este autor-narrador-personagem-ator reconhece-se comunicador, portador da mensagem, sem muito questionar moralmente seu conteúdo. Sua preocupação é manter a comunicação fluente, manter a mensagem circulante: "Eu queria ser um outdoor tanto do charmoso ceticismo burguês do Amory Blane quanto do charmoso espírito revolucionário trotskista. Se você não tem isso na sua juventude, você está morto" (Faustini, 2009, p. 69). 
O que mais importa para esse autor-narrador-personagem-ator é a liberdade, valor do qual Exu também é símbolo, tanto no mundo imaginário quanto no mundo real. A liberdade de circulação, mas a liberdade de fazer-se outro, imaginar-se, incorporar-se em outra forma, sem compromissos com uma identidade predefinida, mas que faz real de acordo com o movimento, a fruição.

$\mathrm{Na}$ hora de descer, posicionei o meu rosto no espelho retrovisor do centro do ônibus e vi a máscara. Gostei do que vi. Não se trata de viver algum personagem. Trata-se de poder entregar-se à fruição. De não se preocupar com as reações faciais que você terá de fazer ao encontrar pessoas. No Rio de Janeiro da ficção, a liberdade é total (Faustini, 2009, p. 75).

Exu se manifesta em múltiplos nomes, formas, como quer, seus trabalhos atendem a uma liberdade que muitas vezes contraria lógicas ou morais. Seu aspecto contraventor, na verdade, é o que faz dele símbolo da tomada de voz por parte daqueles que foram subalternados. Exu incorpora-se de cidade, com tudo o que ela tem, a qualquer hora do dia ou da noite, portanto é a melhor expressão da cidade. No Guia afetivo da periferia, o leitor é provocado a permitir-se incorporar esse Exu e dar a forma que quiser a ele, a gozar da liberdade da circulação, a não temer a cidade, seus espaços e tempos: “O que se passa na cabeça das pessoas que cruzam a cidade pela madrugada dentro dos ônibus? Será que a cidade invade o lugar de seus pensamentos? Como cada um constrói sua Autoviação?" (Faustini, 2009, p. 140).

Exu, que, nas religiões brasileiras de matriz africana, tem seu momento apropriado para manifestar-se, também sabe quando deve recolher-se. Estar presente sem ser visto, sem ser manifesto, ecoa outra vez no autor-narrador-personagem-ator do Guia afetivo da periferia, que, mesmo buscando ser visto e reconhecido, também afirma: "De alguma maneira, eu reconhecia os momentos em que devia ser notado e aqueles em que devia passar desapercebido" (Faustini, 2009, p. 79).

Enfim, muitos outros paralelos podem ser traçados entre esse autor-narrador-personagem-ator do livro e o Orixá Exu. Em muitas outras passagens do livro, nota-se como o universo mitológico do Orixá invade a narrativa e potencializa a interpretação dessa obra, que ganha com isso um outro aspecto de originalidade, a meu ver: o de provocar um outro olhar hermenêutico a partir de uma mitologia constelada no contexto sócio-histórico-cultural brasileiro. 


\section{Conclusões}

Reconhecendo a originalidade do primeiro romance de Marcos Vinicius Faustini, procurei neste texto contribuir para a fortuna crítica da obra, apresentando uma interpretação dela a partir de uma hermenêutica que incorpora a mitologia dos Orixás como sua chave principal. A provocação a isso veio da referência feita por Soares no prefácio da obra a Hermes, deus da mitologia grega. Ainda que concordando com Soares, a leitura da obra de Faustini, contudo, levoume a perceber o quanto seu personagem-narrador na verdade corresponde muito a certas características mitológicas do Orixá Exu.

Em um primeiro momento, após breves apontamentos sobre outros estudos da obra de Faustini, argumento sobre o porquê de propor a mitologia dos Orixás como uma hermenêutica literária e o quanto, a meu ver, essa abordagem instaura uma voz de sujeito crítico nascida da experiência sócio-histórico-cultural brasileira e o quanto essa voz é original em um ambiente crítico. Em seguida, aponto alguns elementos descritivos da mitologia do Orixá Exu, entidade mitológica com a qual procedo minha interpretação do personagem-narrador do Guia afetivo da periferia.

Reconheço as limitações que a análise apresenta, considerandose o pouco espaço para o desenvolvimento da mesma. No entanto, a provocação que este texto traz sobre a possibilidade de inserir-se a mitologia dos Orixás como uma hermenêutica literária pode ser uma contribuição relevante não apenas para o estudo da obra de Marcus Vinicius Faustini mas também para outras leituras de outras obras, que encontrem inspiração crítica a partir do contexto cosmológico, epistemológico e ontológico gerado na constituição das religiões brasileiras de matrizes africana e ameríndia.

\section{Referências}

ASSUNÇÃO, Luiz (2010). A transgressão no religioso: Exus e mestres nos rituais de umbanda. Revista Anthropológicas, ano 14, v. 21, n. 1, p. 157-183.

DALCASTAGNÈ, Regina (2014). Deslocamentos urbanos na literatura brasileira contemporânea. Brasiliana - Journal for Brazilian Studies, v. 3, n. 1, p. 31-47. Disponível em: <http://goo.gl/R9nG9W>. Acesso em: 3 jan. 2015. 
DaMATTA, Roberto (1997). A casa e a rua: espaço, cidadania, mulher e a morte no Brasil. 5. ed. Rio de Janeiro: Rocco.

DELGADO, Gabriel Estides (2013). Marcus Vinicius Faustini e a produção literária da biografia. Revista Criação e Crítica, n. 11, p. 36-47. Disponível em: <http://goo.gl/25FO9B>. Acesso em: 3 jan. 2015.

DRUMOND, Rafael (2013). Biografias anônimas. Em tese, Belo Horizonte, v. 19, n. 1, p. 45-58. Disponível em: <http:/ /goo.gl/i5q7DJ>. Acesso em: 3 jan. 2015.

FAUSTINI, Marcos Vinicius (2009). Guia afetivo da periferia. Rio de Janeiro: Aeroplano.

LEHNEN, Leila (2013). Citizenship and crises in contemporary Brazilian literature. Nova York: Palgrave Macmillam.

PRANDI, Reginaldo (2001). Exu, de mensageiro a diabo: sincretismo católico e demonização do Orixá Exu. Revista USP, n. 50, p. 46-63, jun./ago.

PRANDI, Reginaldo (2005). Por que Exu é o primeiro? In: PRANDI, Reginaldo. Segredos guardados. São Paulo: Companhia das Letras. Disponível em: <http:/ /goo.gl/BWp4Ku>. Acesso em: 3 jan. 2015. Texto extraído e modificado do livro.

SANTOS, Juana Elbein dos (1976). Os Nagô e a morte. Petrópolis: Vozes.

SILVA, Vagner Gonçalves da (2005). Concepções religiosas afro-brasileiras e neopentencostais: uma análise simbólica. Revista USP, n. 67, p. 150-175, set./nov.

SOARES, Luiz Eduardo (2009). Prefácio. In: FAUSTINI, Marcus Vinicius. Guia afetivo da periferia. Rio de Janeiro: Aeroplano.

TRINDADE, Liana Sálvia (1985). Exu, símbolo e função. São Paulo: FFLCH/USP. v. 2.

Recebido em julho de 2014.

Aprovado em novembro de 2014.

\section{resumo/abstract}

\section{Escrevendo-se na cidade: Exu e o Guia afetivo da periferia, de Marcus Vinicius Faustini}

Vinicius Mariano de Carvalho

No texto de prefácio ao livro inaugural de Faustini, Luiz Eduardo Soares diz que: “O movimento do texto de Faustini é sinuoso como suas trajetórias 
urbanas, e tortuoso como seu percurso existencial." Essa afirmação abre perspectivas bastante provocantes sobre a concepção fenomenológica presente no texto dessa narrativa inaugural de Faustini. Neste trabalho procuramos analisar como Faustini constrói um narrador/ator que, em vez de escrever a cidade, inscreve-se nesta, contrapondo, com esse movimento performativo, a tendência comum de dividir o espaço urbano em centro $x$ periferia, cidade $x$ favela, asfalto $\mathrm{x}$ morro. Valendo-me da mitologia das religiões afro-brasileiras, analiso como o narrador/ator do Guia afetivo da periferia incorpora características do Orixá Exu e consubstancia uma fenomenologia da cidade.

Palavras-chave: Exu, fenomenologia, cidade, Marcus Vinicius Faustini.

\section{Writing himself in the city: Exu and the Guia afetivo da periferia, de Marcus Vinicius Faustini}

Vinicius Mariano de Carvalho

In the preface to the inaugural book of Marcos Vinicius Faustini, Luiz Eduardo Soares says: "The movement of Faustini's text is sinuous as his urban trajectories, and devious as his existential journey". This statement opens quite provocative perspectives on the phenomenological conception present Faustini's narrative. This paper analyzes how Faustini creates a narrator/actor who, instead of writing the city, writes himself on it. With this performative movement, the author contrasts the common tendency to divide the urban space in center $\mathrm{x}$ periphery, city $\mathrm{x}$ slum, hill $\mathrm{x}$ asphalt. Using the mythology of AfroBrazilian religions, I analyze how the narrator/actor of Guia Afetivo da Periferia incorporates features of the Orixá Exú and consubstantiates the city phenomenologically.

Keywords: Exu, phenomenology, city, Marcus Vinicius Faustini. 